Check for updates

Cite this: RSC Adv., 2017, 7, 53316

Received 14th September 2017

Accepted 6th November 2017

DOI: 10.1039/c7ra10218f

rsc.li/rsc-advances

\section{Phenylacrylonitrile-bridging triphenylene dimers: the columnar liquid crystals with high fluorescence in both solid state and solution $\uparrow$}

\author{
Hongyu Guo, ${ }^{\text {ab }}$ Liangbin Lin, ${ }^{\mathrm{a}}$ Jiabin Qiu ${ }^{\mathrm{ab}}$ and Fafu Yang (D) *ac
}

Herein, three phenylacrylonitrile-bridging triphenylene dimers were prepared by condensation and etherification procedure in moderate yields. They exhibited the ordered hexagonal columnar mesophase based on the strong columnar stacking-induced action of two triphenylene units. A subtle balance between fluorescence decrease and AIE effect existed upon adding $\mathrm{H}_{2} \mathrm{O}$ to the THF solution, resulting in high fluorescence for these novel AIE liquid crystals in both solid state and solution for the first time.

\section{Introduction}

Organic molecules with columnar mesophases have been paid significant attention in the past few decades. ${ }^{1,2}$ Based on their extended $\pi$-stacking arrays for favourable transport of charge carriers along the columnar axis, they have shown broad application prospects in the fields of organic field-effect transistors, organic light-emitting diodes, organic semiconductors, organic photovoltaic cells, and gas sensors. ${ }^{3-7}$ Among all kinds of columnar liquid crystals, the luminescent columnar liquid crystals have attracted significant research interest due to the effective combination of self-healing characteristics of mesophase and intrinsic luminescence capability. ${ }^{8,9}$ For example, using the dyes such as perylene or Bodipy as cores, the luminescent columnar liquid crystals have been prepared successfully. ${ }^{9-21}$ However, although these luminescent liquid crystals exhibited strong emission in solution, they showed weak fluorescence in the solid state because of the aggregation-caused quenching (ACQ) effect.

Recently, aggregation-induced emission (AIE) discovered by Tang's group supplied a new strategy to prepare the fluorescent liquid crystals..$^{22-24}$ As a result, some liquid crystalline molecules bearing AIE groups were prepared. ${ }^{25-36}$ They exhibited good fluorescence in the solid state, but they were practically non luminescent in solution, and it was difficult to form columnar mesophase due to the non-coplanar structures of AIE cores against the effective $\pi-\pi$ packing in column. Since triphenylene derivatives possess strong columnar-stacking abilities, ${ }^{37-47}$

${ }^{a}$ College of Chemistry and Materials Science, Fujian Normal University, Fuzhou 350007, P. R. China. E-mail: yangfafu@fjnu.edu.cn

${ }^{b}$ Fujian Key Laboratory of Polymer Materials, Fuzhou 350007, P. R. China

${ }^{c}$ Fujian Provincial Key Laboratory of Advanced Materials Oriented Chemical Engineering, Fuzhou 350007, P. R. China

$\dagger$ Electronic supplementary information (ESI) available: Experimental details, supporting figures and table. See DOI: 10.1039/c7ra10218f lately, we have prepared the AIE liquid crystals of triphenylenediphenylacrylonitrile derivatives with the ordered hexagonal columnar mesophase based on the columnar stacking-induced action of triphenylene units. ${ }^{48}$ Although the strong fluorescence in the solid state was observed based on the AIE effect of diphenylacrylonitrile units, the crystals still emitted weakly in good solvents such as THF and $\mathrm{CH}_{2} \mathrm{Cl}_{2}$. Most recently, to attain efficient fluorescence in both the solution and solid state, Tang's group has prepared a triphenylamine derivative that possesses not only good emission in solution based on considerable rigidity with limited intramolecular rotation, but also excellent fluorescence in the solid state due to the substantial twisting conformation. ${ }^{49}$ Inspired by this successful strategy, herein, we report the first columnar AIE liquid crystals with high fluorescence in both the solution and solid state. The columnar mesophase was induced by two triphenylene units, and the fluorescence was emitted by the phenylacrylonitrile group. The subtle balance between fluorescence decrease and AIE effect was responsible for the high fluorescence in both the solution and solid state.

\section{Results and discussion}

\section{Synthesis}

Because triphenylene-diphenylacrylonitrile derivatives have a good AIE effect but show weak fluorescence in solution, ${ }^{48}$ in this research, two diphenylacrylonitrile units were integrated into one conjugated system as a luminogen. Due to the extended rigidity of the conjugated structure, the crystals can emit effectively in solution, and the restriction of intramolecular rotation would produce the AIE effect; on the other hand, due to the large rigidity structure of this kind of phenylacrylonitrile moiety, two triphenylene units with strong columnar-induced abilities were bridged on it to ensure the formation of the columnar mesophase. The synthetic routes are illustrated in Scheme 1. By the condensation reaction of 

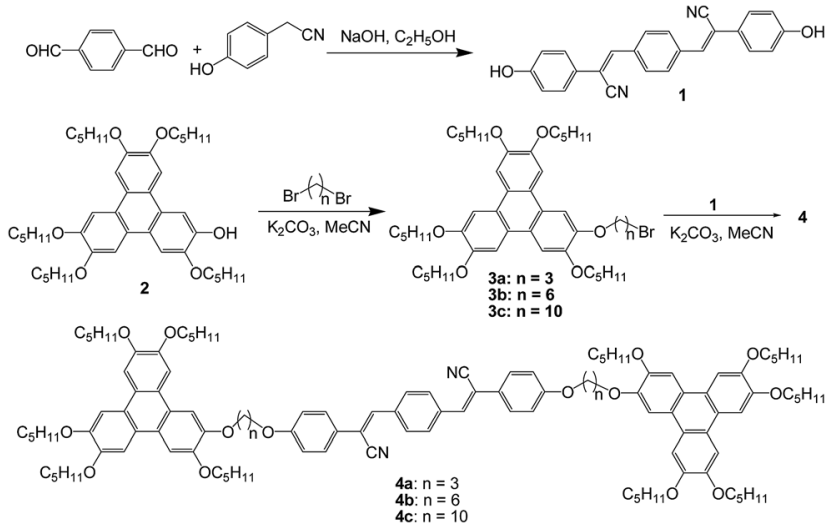

Scheme 1 Synthetic routes of target compounds $4 a, 4 b$, and $4 c$.

4-hydroxyphenyl acetonitrile with terephthalaldehyde in a $\mathrm{NaOH} / \mathrm{EtOH}$ system, the phenylacrylonitrile derivative $\mathbf{1}$ with two terminal hydroxyl groups was prepared in a yield of $78 \%$. Treatment of monohydroxytriphenylene 2 with excess dibromoalkane in a $\mathrm{K}_{2} \mathrm{CO}_{3} / \mathrm{MeCN}$ system afforded triphenylene derivatives $3 \mathbf{a}, 3 \mathbf{b}$, and $3 \mathbf{c}$ in the yields of $66-80 \%$ after column chromatography. Furthermore, the target compounds $\mathbf{4 a}, \mathbf{4 b}$, and $\mathbf{4 c}$ were obtained conveniently by the etherification of the compound $\mathbf{1}$ with the compounds $\mathbf{3 a}, \mathbf{3} \mathbf{b}$, and $\mathbf{3} \mathbf{c}$ in the $\mathrm{K}_{2} \mathrm{CO}_{3} /$ MeCN system, respectively. The yields were as high as $72-84 \%$ after column chromatography.

The structures of the compounds $4 \mathbf{a}, \mathbf{4 b}$, and $\mathbf{4 c}$ were characterized by the ${ }^{1} \mathrm{H}$ NMR spectra, ${ }^{13} \mathrm{C}$ NMR spectra, MALDI-TOFMS spectra, and HR-MS spectra. They exhibited the corresponding molecular ion peaks in mass spectrometry spectra. The deviations of molecular weights were less than $5 \mathrm{ppm}$, indicating the accomplishment of the condensation on two hydroxyl groups of compound 1. In the ${ }^{1} \mathrm{H}$ NMR spectra, the proton signals agreed well with the structures. Especially, the splits of ArH were observed clearly (see ESI $\dagger$ ). The ${ }^{13} \mathrm{C}$ NMR spectra also supported these structures unambiguously.

\section{Mesomorphic properties}

The mesomorphic properties of the compounds $\mathbf{4 a}, \mathbf{4 b}$, and $\mathbf{4 c}$ were investigated by differential scanning calorimetry (DSC), polarizing optical microscopy (POM), and X-ray diffraction (XRD). The changes of DSC traces for second heating and cooling are presented in Fig. 1. The corresponding phase transition temperatures and enthalpy changes are listed in Table 1. All these samples exhibited the reversible phase transition with two peaks upon cooling and second heating. The phase transition peaks for the sample $4 \mathrm{a}$ appeared at $55.2{ }^{\circ} \mathrm{C}$ and $95.8{ }^{\circ} \mathrm{C}$ upon cooling and at $64.5^{\circ} \mathrm{C}$ and $119.2^{\circ} \mathrm{C}$ upon second heating. Sample $4 \mathbf{b}$ showed the phase transition at $18.0^{\circ} \mathrm{C}$ and $73.2^{\circ} \mathrm{C}$ on cooling and at $25.9{ }^{\circ} \mathrm{C}$ and $81.8^{\circ} \mathrm{C}$ upon second heating. For the sample $4 \mathrm{c}$, the broad thermal peaks at $10.1{ }^{\circ} \mathrm{C}$ on cooling and at $12.0^{\circ} \mathrm{C}$ on second heating were observed, and the small peaks at $61.2^{\circ} \mathrm{C}$ on cooling and at $65.7^{\circ} \mathrm{C}$ on second heating emerged. These data suggested the thermal process of crystalline phase-mesophase-isotropic phase for samples $\mathbf{4 a}, \mathbf{4 b}$, and

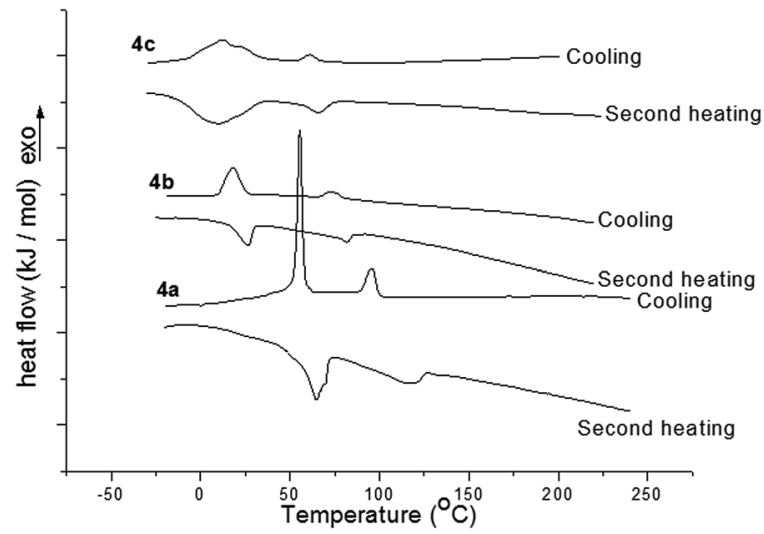

Fig. 1 The DSC traces of the compounds $4 a, 4 b$, and $4 c$ upon second heating and cooling (scan rate $10^{\circ} \mathrm{C} \mathrm{min}^{-1}$ ).

Table 1 Transition temperatures $\left({ }^{\circ} \mathrm{C}\right)$ and enthalpy changes $\left(\mathrm{KJ} \mathrm{mol}^{-1}\right)$ of the samples $4 a, 4 b$, and $4 c$

\begin{tabular}{llll}
\hline Compd. & Phase transition $^{a}$ & Heating scan $T(\Delta H)$ & Cooling scan $T(\Delta H)$ \\
\hline 4a & Cr-Col & $64.5(24.5)$ & $55.2(21.8)$ \\
& Col-Iso & $119.2(12.6)$ & $95.8(10.2)$ \\
$4 \mathbf{b}$ & Cr-Col & $25.9(16.9)$ & $18.0(18.1)$ \\
& Col-Iso & $81.8(6.8)$ & $73.2(5.3)$ \\
$4 \mathbf{c}$ & Cr-Col & $10.1(14.3)$ & $12.0(12.6)$ \\
& Col-Iso & $65.7(4.2)$ & $61.2(3.9)$
\end{tabular}

${ }^{a} \mathrm{Cr}=$ crystalline, $\mathrm{Col}=$ columnar mesophase, Iso $=$ isotropic.

4c. Along with an increase in the length of the alkyl bridging chains, the phase transition temperatures decreased orderly with the trend of $\mathbf{4 c}<\mathbf{4 b}<\mathbf{4 a}$. The broad peaks and the hysteresis phenomena could be ascribed to the viscous morphology of these samples with high molecular weights. All the DSC analyses indicated that although the large rigid structure of two phenylacrylonitrile units were used as bridging spacers, the compounds $\mathbf{4 a}, \mathbf{4 b}$, and $\mathbf{4 c}$ possessed good liquid crystalline behaviors due to the strong columnar stackinginduced action of two triphenylene units. The longer alkyl bridging chains resulted in the lower phase transition temperatures.

The observation using POM also supported the presence of the mesophase for the samples $\mathbf{4 a}, \mathbf{4 b}$, and $\mathbf{4 c}$. At the phase transition temperatures shown in the DSC curves, the corresponding phase transition processes were observed. Just like the compounds $\mathbf{4 b}$ and $\mathbf{4 c}$, compound $4 \mathbf{a}$ also exhibited the clear fluid in mesophase via microscopic observation although its enthalpy of the Col-Iso transition was obviously larger than that of the compounds $\mathbf{4 b}$ and $\mathbf{4 c}$; this might be ascribed to the influence of the short spacer. By cooling slowly from the isotropic phase, the clear textures appeared gradually. Fig. 2 presents the textures of the sample $4 a$ at $75{ }^{\circ} \mathrm{C}$ and those of the samples $\mathbf{4 b}$ and $4 \mathbf{c}$ at $40^{\circ} \mathrm{C}$. The typical pseudo-confocal conic textures indicated the columnar mesophase for these samples, which were further confirmed by the XRD analysis. 


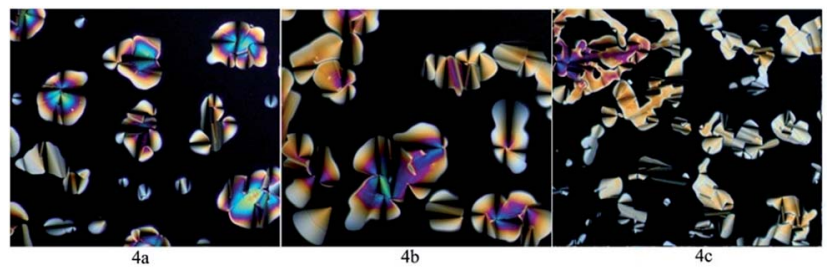

Fig. 2 The mesophase textures observed using POM on cooling at $75^{\circ} \mathrm{C}$ for $4 \mathrm{a}$ and $40^{\circ} \mathrm{C}$ for $4 \mathrm{~b}$ and $4 \mathrm{c}(\times 400)$.

The XRD traces for the samples $\mathbf{4 a}, \mathbf{4 b}$, and $\mathbf{4 c}$ at mesophase were investigated to study the liquid crystalline molecular stacking behavior. The results are illustrated in Fig. 3. It can be seen that all of them exhibited three peaks in the small-angle region. Based on the Bragg equation of $d=\lambda /(2 \sin \theta)$, the peaks of the sample $4 \mathbf{a}$ at $2.91^{\circ}, 5.05^{\circ}$, and $5.83^{\circ}$ suggested the $d$ spacings of $30.33 \AA$, $17.51 \AA$, and $15.16 \AA$, respectively. The reflections for the sample $4 \mathrm{~b}$ were at $2.95^{\circ}, 5.10^{\circ}$, and $5.90^{\circ}$, indicating the corresponding $d$-spacings of $29.93 \AA, 17.29 \AA$, and 14.97 $\AA$. The sample $4 \mathrm{c}$ had the $d$-spacings of $29.55 \AA$, $17.06 \AA$, and $14.77 \AA$ derived from the peaks of $2.99^{\circ}, 5.18^{\circ}$, and $5.99^{\circ}$, respectively. All these data of $d$-spacings were in well agreement with the ratio of $1: 1 / \sqrt{ } 3: 1 / 2$; this implied the reflection signals for (100), (110), and (200) planes of hexagonal columnar mesophase. In the wide angle region, the broad halos at the refection of $16-27^{\circ}$ (3.4-5.5 $\AA$ approximately) could be attributed to the signals of very short correlation length of the molten alkyl chains. The weak peaks at $24.17^{\circ}, 24.27^{\circ}$, and $24.74^{\circ}$ for the samples $\mathbf{4 a}, \mathbf{4 b}$, and $\mathbf{4 c}$, indicating the $d$-spacings of $3.68 \AA$, $3.66 \AA$, and $3.60 \AA$, respectively, were the typical reflections for the intracolumnar $\pi-\pi$ interaction of the columnar liquid crystals. All these data suggested that the compounds $\mathbf{4 a}, \mathbf{4 b}$, and $4 \mathbf{c}$ possessed an ordered hexagonal columnar mesophase, which were in accordance with the POM observation. Furthermore, based on these XRD data, the lattice parameter $\alpha$ for the compounds $\mathbf{4 a}, \mathbf{4 b}$, and $\mathbf{4 c}$ could be calculated as $35.02 \AA$, $34.56 \AA$, and $34.12 \AA$, respectively. These values were approximately in accordance with the diameter of one triphenylene column. Thus, the possible schematic of the columnar layered

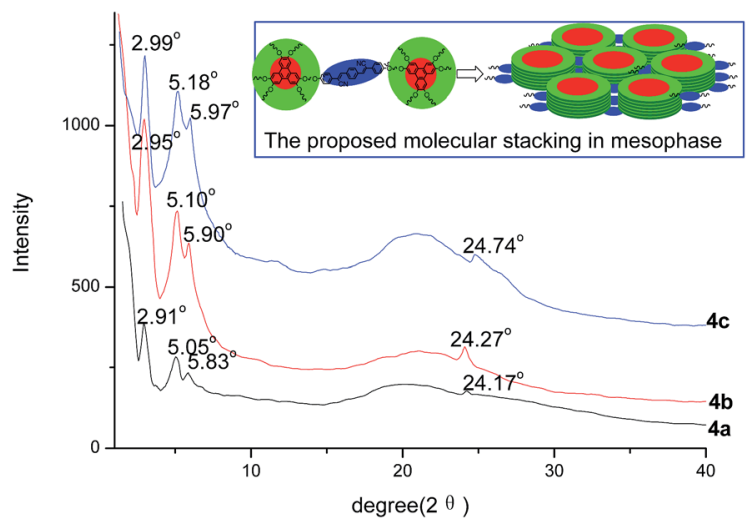

Fig. 3 XRD traces at $75{ }^{\circ} \mathrm{C}$ for $4 \mathrm{a}$ and $40{ }^{\circ} \mathrm{C}$ for $4 \mathrm{~b}$ and $4 \mathrm{c}$, and the proposed molecular stacking model for $4 a, 4 b$, and $4 c$. molecular arrangement was proposed as the square inserted in Fig. 3, in which the discs resided in separate columns, with the bridge spanning the distance between columns. Combining all these studies of DSC, POM, and XRD analyses, it could be concluded that the unfavorable influence of the large rigid structure of phenylacrylonitrile for columnar mesophase was compensated by the strong columnar stacking-induced action of two triphenylene units. The compounds $\mathbf{4 a}, \mathbf{4 b}$, and $\mathbf{4 c}$ possessed a good reversible liquid crystalline behavior with an ordered hexagonal columnar mesophase.

\section{Photophysical properties}

The photophysical behaviors of the samples $\mathbf{4 a}, \mathbf{4 b}$, and $\mathbf{4 c}$ were studied to explore their luminescence properties. Their UV-vis absorption spectra in series of solvents with increased polarities are shown in Fig. S13-S15. $\dagger$ It can be seen that the $\lambda_{\text {abs }}$ of the samples $\mathbf{4 a}, \mathbf{4 b}$, and $\mathbf{4 c}$ were at about $390 \mathrm{~nm}$ in toluene and exhibited a small blue shift with an increase of solvent polarities to $384 \mathrm{~nm}$ in DMF finally. The fluorescence spectra of the samples $\mathbf{4 a}, \mathbf{4 b}$, and $\mathbf{4 c}$ in toluene, $\mathrm{CH}_{2} \mathrm{Cl}_{2}, \mathrm{CHCl}_{3}, \mathrm{THF}$, and DMF are illustrated in Fig. S16-S18 $\dagger$ and 4 for $\mathbf{4 b}$ as the representative sample. With an increase of solvent polarity, their emission peaks presented obvious red shifts and the fluorescence intensity decreased correspondingly. However, the spectral changes were small in toluene, $\mathrm{CH}_{2} \mathrm{Cl}_{2}, \mathrm{CHCl}_{3}$, and THF, except for the DMF solution. These spectral changes might be ascribed to the intramolecular charge transfer effect and/or low solubility in highly polar solvents.

Furthermore, the fluorescence behaviors of the samples $\mathbf{4 a}$, 4b, and 4c in $\mathrm{THF} / \mathrm{H}_{2} \mathrm{O}$ mixtures with different fractions of $\mathrm{H}_{2} \mathrm{O}$ were investigated. All these samples have good solubility in THF and are sparingly solubility in the $\mathrm{THF} / \mathrm{H}_{2} \mathrm{O}$ mixture. Their fluorescence spectra in the $\mathrm{THF} / \mathrm{H}_{2} \mathrm{O}$ mixture and the plots of changes for emission peak intensity are exhibited in Fig. S19S24. $\dagger$ Fig. 5 illustrates the spectra and plot for sample $\mathbf{4 b}$ as the representative sample. It can be observed that being different from the typical AIE molecules with little emission in pure THF solution, samples $\mathbf{4 a}, \mathbf{4 b}$, and $\mathbf{4 c}$ possess strong emission due to considerable rigidity with limited intramolecular rotation of large conjugated phenylacrylonitrile moiety. With the addition

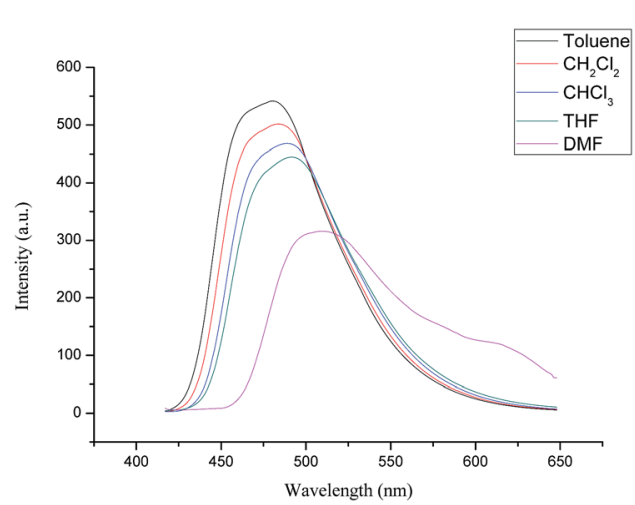

Fig. 4 The emission spectra of the compound $4 \mathrm{~b}$ in different solvents $\left(1.0 \times 10^{-5} \mathrm{M}\right)$ with the excitation wavelength of $390 \mathrm{~nm}$. 

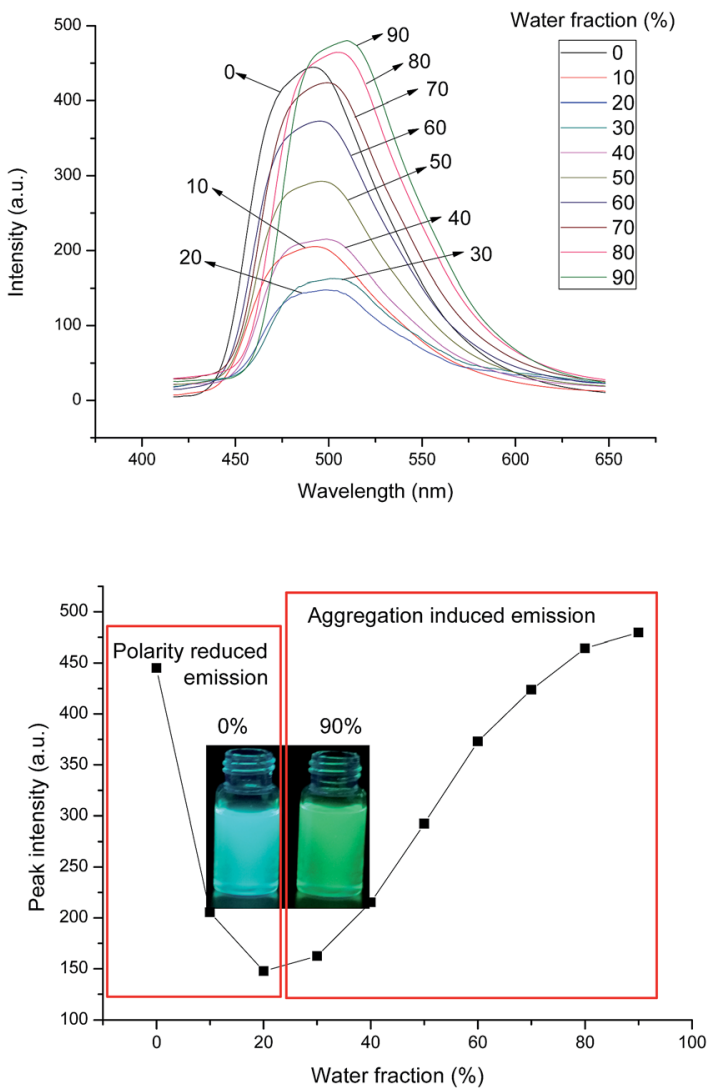

Fig. 5 (Up) The emission spectra of the compound 4b in $\mathrm{H}_{2} \mathrm{O} / \mathrm{THF}$ mixtures with different water fractions $\left(1.0 \times 10^{-5} \mathrm{M}\right)$. (Down) The changes in peak intensity and emission images of the compound $4 \mathrm{~b}$ in $\mathrm{H}_{2} \mathrm{O} / \mathrm{THF}$ mixtures with different water fractions $\left(\lambda_{\mathrm{ex}}=390 \mathrm{~nm}\right.$ ).

of water to the THF solution, the emission intensity reduced rapidly. As the water contents attained $20-30 \%$, the samples $4 a$, $\mathbf{4 b}$, and $4 \mathbf{c}$ still maintained moderate fluorescence although the emission intensities were at the lowest values among various contents of water. Combining the abovementioned absorption and fluorescence investigation in various solvents, the decrease of fluorescence in the $\mathrm{THF} / \mathrm{H}_{2} \mathrm{O}$ mixture might be attributed to the intramolecular charge transfer effect and/or the low solubility in highly polar solvents. The addition of water increased the polarity of solvents and led to both stronger charge separation and dipole moment for the samples $\mathbf{4 a}, \mathbf{4 b}$, and $\mathbf{4 c}$ and low solubility in the $\mathrm{THF} / \mathrm{H}_{2} \mathrm{O}$ mixture; this resulted in the decrease of fluorescence intensity correspondingly. On the other hand, the phenylacrylonitrile unit is a typical AIE unit, which produces gradually enhanced fluorescence with the addition of water to the $\mathrm{THF} / \mathrm{H}_{2} \mathrm{O}$ mixture. Thus, when the contents of water were higher than $50 \%$ for $\mathbf{4 a}$ and $30 \%$ for $\mathbf{4 b}$ and $\mathbf{4 c}$, the fluorescence intensities increased dramatically. When the contents of water approached $90 \%$, the emissions were even stronger than those in the pure THF solution. Moreover, with the addition of water, the fluorescence peaks of the samples $\mathbf{4 a}, \mathbf{4 b}$, and $\mathbf{4 c}$ became broader and exhibited a slight red shift. These phenomena suggested that the strong AIE process occurred when water was added to the solutions. The increased fluorescence based on the AIE process made up
Table 2 The photophysical data for samples $4 a, 4 b$, and $4 c$

\begin{tabular}{llllll}
\hline Sample & $\begin{array}{l}\lambda_{\max } / \mathrm{nm} \\
(\mathrm{THF})\end{array}$ & $\begin{array}{l}\lambda_{\mathrm{em}} / \mathrm{nm} \\
(\mathrm{THF})\end{array}$ & $\Phi_{\mathrm{F}}(\mathrm{THF})$ & $\begin{array}{l}\Phi_{\mathrm{F}} \\
\left(10_{\text {THF }}: 90_{\text {water }}\right)\end{array}$ & $\begin{array}{l}\Phi_{\mathrm{F}} \\
\text { (powder) }\end{array}$ \\
\hline 4a & 386 & 485 & 18.8 & 21.9 & 8.3 \\
4b & 386 & 491 & 19.0 & 22.1 & 8.7 \\
4c & 387 & 492 & 19.1 & 22.3 & 8.9
\end{tabular}

well for the previous fluorescence decrease. These results also implied a subtle balance between fluorescence decrease and AIE effect while adding water to the THF solution. This balance resulted in the strong fluorescence for the samples $\mathbf{4 a}, \mathbf{4 b}$, and $4 \mathbf{c}$ in both the pure THF solution and $\mathrm{THF} / \mathrm{H}_{2} \mathrm{O}$ mixture with high contents of water although a relatively low fluorescence emerged at moderate contents of water. This kind of balance between fluorescence decrease and AIE phenomenon was similar to the recently reported previous studies on fluorescent probe, fumaronitrile-based fluorogen, and piezofluorochromic molecule. ${ }^{50-52}$ Moreover, the fluorescence spectra in powder were obtained (Fig. S25 $\dagger$ ), and the fluorescence quantum yields $\left(\Phi_{\mathrm{F}}\right)$ are summarized in Table 2. It can be seen that the samples $\mathbf{4 a}, \mathbf{4 b}$, and $\mathbf{4 c}$ possess high fluorescence with the $\Phi_{\mathrm{F}}$ values around $20 \%$ in both the pure THF solution and $\mathrm{THF} / \mathrm{H}_{2} \mathrm{O}$ mixture with $90 \%$ of water. The $\Phi_{\mathrm{F}}$ values in powder also attained around $9 \%$, indicating that the samples could emit fluorescence well in the solid state. Furthermore, the fluorescence emission in the solid state and mesophase of the compound 4a were observed using a handheld $365 \mathrm{~nm}$ UV lamp as the excitation source. The fluorescence images in the solid state $\left(26^{\circ} \mathrm{C}\right.$ before heating), mesophase $\left(90^{\circ} \mathrm{C}\right)$, and solid state $\left(30^{\circ} \mathrm{C}\right.$ after cooling) are exhibited in Fig. S26. $\dagger$ It can be seen that the compound $4 a$ emits good fluorescence in both the solid state and mesophase. The fluorescence wavelength in the mesophase showed obvious blue-shift in comparison with that in the solid state; this is a normal phenomenon for the thermochromism of fluorescent liquid crystals. ${ }^{34}$ Based on all the abovementioned analysis of photophysical data, it could be summarized that the samples $\mathbf{4 a}, \mathbf{4 b}$, and $\mathbf{4 c}$ possessed good fluorescence emission in pure THF solution, $\mathrm{THF} / \mathrm{H}_{2} \mathrm{O}$ mixture, and solid state.

\section{Conclusions}

In conclusion, three phenylacrylonitrile-bridging triphenylene dimers $\mathbf{4 a}, \mathbf{4 b}$, and $\mathbf{4 c}$ were designed and synthesized in moderate yields. The studies on mesomorphic property explored that although the large rigid structure of diphenylacrylonitrile units was introduced, the compounds $\mathbf{4 a}, \mathbf{4 b}$, and $\mathbf{4 c}$ exhibited the ordered hexagonal columnar mesophase based on the strong columnar stacking-induced action of two triphenylene units. Moreover, they exhibited high fluorescence in both the solid state and solution. The subtle balance between fluorescence decrease and AIE effect was proposed to be responsible for these interesting fluorescence phenomena. The compounds $\mathbf{4 a}, \mathbf{4 b}$, and $\mathbf{4 c}$ were the first columnar AIE liquid crystals with high fluorescence in both the solution and solid state. This 
study supplies a new method for the design and synthesis of the novel fluorescent liquid crystals.

\section{Experimental}

\section{General}

All chemical reagents, organic solvents, and inorganic reagents were purchased from Aladdin Reagent Co. Ltd. They were purified by the standard anhydrous methods before use. TLC analysis was conducted on pre-coated glass plates. Column chromatography was carried out using silica gel (200-300 mesh). NMR spectra were obtained in $\mathrm{CDCl}_{3}$ at $26{ }^{\circ} \mathrm{C}$ using a BrukerARX 400 instrument. Chemical shifts were obtained in ppm with tetramethylsilane (TMS) as the internal standard. MS spectra were obtained using a Bruker mass spectrometer. The compounds $\mathbf{3 a}$ and $\mathbf{3} \mathbf{b}$ were synthesized according to the reported literature. ${ }^{53}$ Compound $3 \mathbf{c}$ was prepared by the literature method. ${ }^{38}$ UV-vis spectra were obtained using the Varian UV-vis spectrometer. Fluorescence spectra were obtained using a conventional quartz cell $(10 \times 10 \times 45 \mathrm{~mm})$ via a Hitachi $\mathrm{F}$ 4500 spectrometer. The excitation and emission slits were $5 \mathrm{~nm}$ wide. The fluorescence absolute $\Phi_{\mathrm{F}}$ values were obtained using an Edinburgh Instruments FLS920 Fluorescence Spectrometer with a 6-inch integrating sphere. A polarized optical microscopy (Leica DMRX) image was obtained using a hot stage (Linkam THMSE 600) to investigate the phase transitions. Thermal analysis of the materials was carried out using a differential scanning calorimeter (DSC) (Thermal Analysis Q100) under a $\mathrm{N}_{2}$ atmosphere at a scanning rate of $10{ }^{\circ} \mathrm{C} \mathrm{min}^{-1}$. XRD experiments were conducted by SEIFERT-FPM (XRD7) using $\mathrm{Cu}$ $\mathrm{K} \alpha 1.5406 \AA$ as the radiation source with $40 \mathrm{kV}$ and $30 \mathrm{~mA}$ power.

\section{Synthetic procedure for the compound 1}

A mixture of 4-hydroxyphenyl acetonitrile $(0.51 \mathrm{~g}, 3.8 \mathrm{mmol})$, terephthalaldehyde $(0.25 \mathrm{~g}, 1.9 \mathrm{mmol})$, and $\mathrm{NaOH}(0.30 \mathrm{~g}, 7.5$ $\mathrm{mmol}$ ) in a $30 \mathrm{~mL}$ of EtOH solution was stirred for $12 \mathrm{~h}$ at room temperature. The reaction was monitored by the TLC technique, indicated by the disappearance of the starting materials. Then, $20 \mathrm{~mL}$ of $\mathrm{HCl}$ solution $(1 \mathrm{M})$ was added to the reaction system. The precipitate was formed and obtained. The obtained precipitate was further purified by recrystallization in $\mathrm{MeOH} /$ water $(1: 1$, $\mathrm{v} / \mathrm{v})$. After drying over vacuum, compound 1 was obtained as a pale yellow solid in a yield of $78 \% .{ }^{1} \mathrm{H}$ NMR $\left(400 \mathrm{MHz}, \mathrm{CHCl}_{3}\right) \delta$ : $7.01(\mathrm{~d}, J=8.0 \mathrm{~Hz}, 4 \mathrm{H}, \operatorname{ArH}), 7.46$ (s, 2H, CH=C), 7.66 (d, $J=$ $8.0 \mathrm{~Hz}, 4 \mathrm{H}, \mathrm{ArH}), 7.95$ (s, 4H, ArH), 8.22 (s, 2H, OH). MALDI-TOFMS calcd $\left(\mathrm{C}_{24} \mathrm{H}_{16} \mathrm{~N}_{2} \mathrm{O}_{2}\right)$ for $m / z=364.2$, found: $m / z=387.2$ $\left(\mathrm{MNa}^{+}\right), 403.2\left(\mathrm{MK}^{+}\right)$.

\section{Synthetic procedure for the compounds $4 a, 4 b$, and $4 \mathrm{c}$}

Under the protection of $\mathrm{N}_{2}$ atmosphere, a mixture of compound 3a (3b or 3c, $0.5 \mathrm{mmol}$ ), compound 1 ( $0.091 \mathrm{~g}, 0.25 \mathrm{mmol}), \mathrm{K}_{2} \mathrm{CO}_{3}$ $(0.28 \mathrm{~g}, 2.0 \mathrm{mmol})$, and $\mathrm{KI}(0.1 \mathrm{~g}, 0.6 \mathrm{mmol})$ was stirred and refluxed in dry MeCN $(30 \mathrm{~mL})$ for $48 \mathrm{~h}$ at $85{ }^{\circ} \mathrm{C}$. The completion of the reaction by TLC technique was indicated by the disappearance of reactants. After reaction, the mixture was cooled, treated with $50 \mathrm{~mL}$ of the $\mathrm{HCl}$ solution $(1 \mathrm{M})$, and extracted with $50 \mathrm{~mL}$ of
$\mathrm{CHCl}_{3}$. The $\mathrm{CHCl}_{3}$ layer was separated and concentrated under reduced pressure. The obtained residue was further purified by rapid column chromatography using ethyl acetate/hexane $(1: 5, \mathrm{v} / \mathrm{v})$ as an eluent. After drying, the compounds $\mathbf{4 a}, \mathbf{4 b}$, and 4c were obtained as pale yellow solid in the yields of $72 \%, 78 \%$, and $84 \%$, respectively. Compound $4 \mathbf{a}:{ }^{1} \mathrm{H}$ NMR (400 MHz, $\mathrm{CDCl}_{3}$ ) $\delta: 7.93$ (s, 4H, ArH), 7.87 (s, 2H, TpH), 7.83 (bs, 10H, TpH), 7.61 (d, $=8.0 \mathrm{~Hz}, 4 \mathrm{H}, \mathrm{ArH}), 7.39(\mathrm{~s}, 2 \mathrm{H}, \mathrm{CH}=\mathrm{CCN}), 7.02(\mathrm{~d}, J=8.0 \mathrm{~Hz}, 4 \mathrm{H}$, $\operatorname{ArH}), 4.45\left(\mathrm{t}, J=8.0 \mathrm{~Hz}, 4 \mathrm{H}, \mathrm{OCH}_{2}\right), 4.35\left(\mathrm{t}, J=8.0 \mathrm{~Hz}, 4 \mathrm{H}, \mathrm{OCH}_{2}\right)$, $4.23\left(\mathrm{t}, J=8.0 \mathrm{~Hz}, 20 \mathrm{H}, \mathrm{OCH}_{2}\right), 1.40-2.47\left(\mathrm{~m}, 64 \mathrm{H}, \mathrm{CH}_{2}\right), 0.97(\mathrm{t}$, $\left.30 \mathrm{H}, J=8.0 \mathrm{~Hz}, 30 \mathrm{H}, \mathrm{CH}_{3}\right) .{ }^{13} \mathrm{C} \mathrm{NMR}\left(100 \mathrm{MHz} \mathrm{CDCl}_{3}\right) \delta \mathrm{ppm}$ : 160.17 , 148.86, 148.37, 138.40, 135.30, 129.26, 127.27, 126.85, $123.71,123.29,117.96,115.04,111.92,107.67,107.24,107.03$, 69.47, 66.06, 64.79, 53.45, 31.85, 29.79, 29.14, 18.38, 22.48, 13.86. MALDI-TOF-MS calcd for $\mathrm{m} / \mathrm{z}=1794.1$, found: $\mathrm{m} / \mathrm{z}=1795.5$ $\left(\mathrm{MH}^{+}\right)$. HR-MS(ESI) $\left(\mathrm{C}_{116} \mathrm{H}_{148} \mathrm{~N}_{2} \mathrm{O}_{14}\right)[\mathrm{M}]^{+}$: calcd: 1794.0958 . Found: 1794.0949. Compound 4b: ${ }^{1} \mathrm{H}$ NMR (400 $\left.\mathrm{MHz} \mathrm{CDCl}_{3}\right) \delta: 7.91$ (s, 4H, ArH), 7.84 (bs, 12H, TpH), 7.61 (d, J=8.0 Hz, 4H, ArH), 7.37 $(\mathrm{s}, 2 \mathrm{H}, \mathrm{CH}=\mathrm{CCN}), 6.95(\mathrm{~d}, J=8.0 \mathrm{~Hz}, 4 \mathrm{H}, \mathrm{ArH}), 4.23(\mathrm{t}, J=8.0 \mathrm{~Hz}$, $\left.24 \mathrm{H}, \mathrm{OCH}_{2}\right), 4.04\left(\mathrm{t}, J=8.0 \mathrm{~Hz}, 4 \mathrm{H}, \mathrm{OCH}_{2}\right), 1.39-2.05(\mathrm{~m}, 76 \mathrm{H}$, $\mathrm{CH}_{2}$ ), $0.98\left(\mathrm{t}, 30 \mathrm{H}, J=8.0 \mathrm{~Hz}, 30 \mathrm{H}, \mathrm{CH}_{3}\right) .{ }^{13} \mathrm{C}$ NMR $(100 \mathrm{MHz}$, $\left.\mathrm{CDCl}_{3}\right) \delta \mathrm{ppm}: 160.26,148.99,138.18,135.40,130.10,129.45$, 129.07, 127.36, 126.53, 123.60, 117.79, 115.01, 112.24, 107.34. MALDI-TOF-MS calcd for $m / z=1878.2$, found: $\mathrm{m} / z=1880.6$ $\left(\mathrm{MH}^{+}\right)$. HR-MS(ESI) $\left(\mathrm{C}_{122} \mathrm{H}_{160} \mathrm{~N}_{2} \mathrm{O}_{14}\right)[\mathrm{M}]^{+}$: calcd: 1878.1897 . Found: 1878.1868. Compound 4c: ${ }^{1} \mathrm{H}$ NMR (400 MHz, $\left.\mathrm{CDCl}_{3}\right) \delta: 7.83$ (bs, 12H, TpH), 7.81 (s, 4H, ArH), 7.56 (d, J=8.0 Hz, 4H, ArH), 7.27 $(\mathrm{s}, 2 \mathrm{H}, \mathrm{CH}=\mathrm{CCN}), 6.90(\mathrm{~d}, J=8.0 \mathrm{~Hz}, 4 \mathrm{H}, \mathrm{ArH}), 4.24(\mathrm{t}, J=8.0 \mathrm{~Hz}$, $\left.24 \mathrm{H}, \mathrm{OCH}_{2}\right), 3.96\left(\mathrm{t}, J=8.0 \mathrm{~Hz}, 4 \mathrm{H}, \mathrm{OCH}_{2}\right), 1.33-2.03(\mathrm{~m}, 92 \mathrm{H}$, $\mathrm{CH}_{2}$ ), 0.98 (t, 30H, $\left.J=8.0 \mathrm{~Hz}, 30 \mathrm{H}, \mathrm{CH}_{3}\right) .{ }^{13} \mathrm{C} \mathrm{NMR}(100 \mathrm{MHz}$, $\left.\mathrm{CDCl}_{3}\right) \delta \mathrm{ppm}: 160.23,148.92,138.19,135.18,132.30,132.00$, 130.19 , 128.92, 127.29, 126.23, 123.60, 117.73, 116.08, 114.93, 114.70, 107.21, 69.64, 68.37, 31.88, 29.76, 29.09, 28.44, 26.24, 25.80, 22.64, 14.18. MALDI-TOF-MS calcd for $m / z=1990.3$, found: $m / z=$ $1992.9\left(\mathrm{MH}^{+}\right)$. HR-MS(ESI $\quad\left(\mathrm{C}_{130} \mathrm{H}_{176} \mathrm{~N}_{2} \mathrm{O}_{14}\right) \quad\left[\mathrm{MNH}_{4}\right]^{+}$: calcd: 2008.3493. Found: 2008.3415.

\section{Conflicts of interest}

There are no conflicts to declare.

\section{Acknowledgements}

Financial support received from the National Natural Science Foundation of China (No. 21406036) and Fujian Natural Science Foundation of China (No. 2017J01571) is greatly acknowledged. Great thanks for the direction to Prof. Ben Zhong Tang in HKUST.

\section{References}

1 S. Kumar, in Handbook of Liquid Crystals, ed. J. W. Goodby, Wiley VCH, 2014, vol. 4, pp. 467-520.

2 T. Wöhrle, I. Wurzbach, J. Kirres, A. Kostidou, N. Kapernaum, J. Litterscheidt, J. C. Haenle, P. Staffeld, A. Baro, F. Giesselmann and S. Laschat, Chem. Rev., 2016, 116, 1139-1241. 
3 S. Kumar, Chemistry of discotic liquid crystals: from monomers to polymers, CRC press, London, New York, 2010.

4 S. Sergeyev, W. Pisula and Y. H. Geerts, Chem. Soc. Rev., 2007, 36, 1902-1929.

5 T. Kato, N. Mizoshita and K. Kishimoto, Angew. Chem., Int. Ed., 2006, 45, 38-68.

6 S. Laschat, A. Baro, N. Steinke, F. Giesselmann, C. Hagele, G. Scalia, R. Judele, E. Kapatsina, S. Sauer, A. Schreivogel and M. Tosoni, Angew. Chem., Int. Ed., 2007, 46, 4832-4887.

7 S. Kumar, Chem. Soc. Rev., 2006, 35, 83-109.

8 T. Yasuda, H. Ooi, J. Morita, Y. Akama, K. Minoura, M. Funahashi, T. Shimomura and T. Kato, Adv. Funct. Mater., 2009, 19, 411-419.

9 X. Q. Li, X. Zhang, S. Ghosh and F. Würthner, Chem.-Eur. J., 2008, 14, 8074-8078.

10 X. F. Kong, Z. Q. He, Y. N. Zhang, L. P. Mu, C. J. Liang, B. Chen, X. P. Jing and A. N. Cammidge, Org. Lett., 2011, 13, 764-767.

11 M. G. Zhu, H. Y. Guo, F. F. Yang and Z. S. Wang, Liq. Cryst., 2016, 43, 1875-1883.

12 N. Mizoshita, T. Tani and S. Inagaki, Adv. Funct. Mater., 2011, 21, 3291-3298.

13 H. Y. Guo, M. G. Zhu, Z. S. Wang and F. F. Yang, Tetrahedron Lett., 2016, 57, 4191-4195.

14 M. G. Zhu, H. Y. Guo, F. F. Yang and Z. S. Wang, RSC Adv., 2017, 7, 4320-4328.

15 Z. Chen, U. Baumeister, C. Tschierske and F. Würthner, Chem.-Eur. J., 2007, 13, 450-465.

16 X. T. Fang, H. Y. Guo, J. R. Lin and F. F. Yang, Tetrahedron Lett., 2016, 57, 4939-4943.

17 L. Meng, Q. M. Wu, F. F. Yang and H. Y. Guo, New J. Chem., 2015, 39, 72-76.

18 G. A. Bhavsar and S. K. Asha, Chem.-Eur. J., 2011, 17, 1264612658.

19 X. T. Fang, H. Y. Guo, F. F. Yang and J. R. Lin, RSC Adv., 2017, 7, 23657-23662.

20 M. G. Zhu, Z. S. Wang, F. F. Yang and H. Y. Guo, Dyes Pigm., 2016, 133, 387-394.

21 S. K. Gupta, S. Setia, S. Sidiq, M. Gupta, S. Kumar and S. K. Pal, RSC Adv., 2013, 3, 12060-12065.

22 Y. Hong, J. W. Y. Lam and B. Z. Tang, Chem. Soc. Rev., 2011, 40, 5361-5388.

23 M. Wang, G. Zhang, D. Zhang, D. Zhu and B. Z. Tang, J. Mater. Chem., 2010, 20, 1858-1867.

24 Y. Hong, J. W. Y. Lam and B. Z. Tang, Chem. Commun., 2009, 28, 4332-4335.

25 J. H. Wan, L. Y. Mao, Y. B. Li, Z. F. Li, H. Y. Qiu, C. Wang and G. Q. Lai, Soft Matter, 2010, 6, 3195-3210.

26 W. Z. Yuan, Z. Q. Yu, P. Lu, C. M. Deng, J. W. Y. Lam, Z. M. Wang, E. Q. Chen, Y. G. Ma and B. Z. Tang, J. Mater. Chem., 2012, 22, 3323-3326.

27 Y. F. Chen, J. S. Lin, W. Z. Yuan, Z. Q. Yu, J. W. Lam and B. Z. Tang, Sci. China: Chem., 2013, 56, 1191-1196.

28 S. L. Yoon, J. H. Kim, K. S. Kim, J. W. Chung, B. Heinrich, F. Mathevet, P. Kim, B. Donnio, A. J. Attias and D. Kim, Adv. Funct. Mater., 2012, 22, 61-69.
29 D. Y. Zhao, F. Fan, J. Cheng, Y. L. Zhang, K. S. Wong, V. G. Chigrinov, H. D. Kwok, L. Guo and B. Z. Tang, Adv. Opt. Mater., 2015, 3, 199-202.

30 S. M. Morris, M. M. Qasim, D. J. Gardiner, P. J. W. Hands, F. Castles, G. Tu, W. T. S. Huck, R. H. Friend and H. J. Coles, Opt. Mater., 2013, 35, 837-842.

31 S. J. Yoon, J. H. Kim, K. S. Kim, J. W. Chung, B. Heinrich, F. Mathevet, P. Kim, B. Donnio and A. J. Attias, Adv. Funct. Mater., 2012, 22, 61-69.

32 W. P. Jin, N. Shusaku, Y. Seong-Jun, D. Tomoki, S. Jangwon, S. Takahiro and Y. P. Soo, Adv. Mater., 2014, 26, 1354-1359.

33 M. Martinez-Abadía, B. Robles-Hernandez, B. Villacampa, M. R. de la Fuente, R. Giménez and M. B. Ros, J. Mater. Chem. C, 2015, 3, 3038-3048.

34 M. Martinez-Abadía, S. Varghese, B. Milian-Medina, J. Gierschner, R. Giménez and M. B. Ros, Phys. Chem. Chem. Phys., 2015, 17, 11715-11724.

35 M. Martinez-Abadía, S. Varghese, R. Giménez and M. B. Ros, J. Mater. Chem. C, 2016, 4, 2886-2893.

36 W. H. Yu, C. Chen, P. Hu, B. Q. Wang, C. Redshaw and K. Q. Zhao, RSC Adv., 2013, 3, 14099-14106.

37 F. F. Yang, H. Y. Guo, J. W. Xie and J. R. Lin, Eur. J. Org. Chem., 2011, 26, 5141-5145.

38 B. Q. Hong, F. F. Yang, H. Y. Guo and Z. Y. Jiao, Tetrahedron Lett., 2014, 55, 252-255.

39 F. F. Yang, J. Yuan, C. C. Li, H. Y. Guo and X. Y. Yuan, Liq. Cryst., 2014, 41, 137-143.

40 F. F. Yang, Y. M. Zhang, H. Y. Guo and J. R. Lin, Tetrahedron Lett., 2013, 54, 4953-4956.

41 F. F. Yang, H. Y. Guo and J. Vicens, J. Inclusion Phenom. Macrocyclic Chem., 2014, 80, 177-186.

42 S. Kumar, Liq. Cryst., 2009, 36, 607-638.

43 F. F. Yang, B. T. Xu, H. Y. Guo and J. W. Xie, Tetrahedron Lett., 2012, 53, 1598-1602.

44 A. Zelcer, B. Donnio, C. F. Bourgogne, D. Cukiernik and D. Guillon, Chem. Mater., 2007, 19, 1992-2006.

45 F. F. Yang, J. W. Xie, H. Y. Guo, B. T. Xu and C. C. Li, Liq. Cryst., 2012, 39, 1368-1374.

46 F. F. Yang, X. Y. Bai, H. Y. Guo and C. C. Li, Tetrahedron Lett., 2013, 54, 409-413.

47 C. Imrie and P. Henderson, Chem. Soc. Rev., 2007, 36, 20962124.

48 L. B. Lin, H. Y. Guo, X. T. Fang and F. F. Yang, RSC Adv., 2017, 7, 20172-20177.

49 G. Chen, W. B. Li, T. R. Zhou, Q. Peng, D. Zhai, H. X. Li, W. Z. Yuan, Y. M. Zhang and B. Z. Tang, Adv. Mater., 2015, 27, 4496-4501.

50 T. Y. Han, W. Wei, J. Yuan, Y. Duan, Y. P. Li, L. Y. Hu and Y. P. Dong, Talanta, 2016, 150, 104-112.

51 F. F. Han, R. Zhang, Z. M. Zhang, J. G. Su and Z. H. Ni, RSC Adv., 2016, 6, 68178-618184.

52 X. Y. Shen, W. Z. Yuan, Y. Liu, Q. L. Zhao, P. Lu, Y. G. Ma, I. D. Williams, A. J. Qin, J. Z. Sun and B. Z. Tang, J. Phys. Chem. C, 2012, 116, 10541-10547.

53 X. T. Fang, H. Y. Guo, J. R. Lin and F. F. Yang, Tetrahedron Lett., 2016, 57, 4939-4943. 